\title{
MERCADO DE TRABAJO Y FORMACIÓN ENTRE INMIGRANTES LATINOAMERICANOS EN LA COMUNIDAD DE MADRID ${ }^{1}$
}

\author{
POR
}

\author{
VICENTE RODRÍGUEZ \\ SILVIA MARCU
}

Instituto de Economía, Geografía y Demografía. Centro de Ciencias Humanas y Sociales (CSIC)

El artículo estudia la relación existente entre la formación y el empleo inmigrante en la Comunidad de Madrid (CAM), de los inmigrantes procedentes de Ecuador y Colombia. La primera parte aborda los desajustes existentes entre la formación y el empleo haciendo hincapié en el nivel formativo de los inmigrantes en los países de origen, mientras que la segunda parte analiza la necesidad y el valor de la formación para el acceso laboral en el mercado de trabajo madrileño. A partir del análisis del discurso de los inmigrantes y de los técnicos especialistas en el ámbito (entrevistas en profundidad y grupos focales), es posible avanzar en el debate acerca del presente y de las perspectivas de futuro del mercado de trabajo y la inmigración, por una parte, y de los retos y limitaciones de la intervención sociolaboral como vía para la integración del colectivo latinoamericano, por la otra parte.

PAlABRAS Clave: Inmigrantes latinoamericanos, formación y empleo, Comunidad de Madrid, mercado de trabajo.

1 Este trabajo está extraído del proyecto IFECAM (Inmigración, Formación y Empleo en la Comunidad de Madrid), financiado por la Consejería de Empleo y Mujer, 2005-2006, y elaborado por un equipo formado por los Dres. Calatrava, Castro, Melero, Méndez, Marcu y Lardies, y la Licda. Juárez, del Instituto de Economía, Geografía y Demografía (Centro de Ciencias Humanas y Sociales, CSIC), y dirigido por el Dr. Vicente Rodríguez. 
INTRODUCCIÓN. INMIGRANTES ECUATORIANOS Y COLOMBIANOS EN LA COMUNIDAD DE MADRID

España entró en el siglo XXI como país de inmigración, y esta condición se debe, en primer lugar, a su posición geoestratégica como puerta de entrada en Europa y como puente de encuentro entre varios continentes, y, en segundo lugar, como estructura económica que atrae a grandes contingentes de mano de obra inmigrante, como han demostrado una multiplicidad de estudios. Tras la regularización que tuvo lugar entre febrero y mayo de 2005, los inmigrantes de Ecuador, Rumanía, Colombia y Marruecos vieron incrementados su número en España ${ }^{2}$, y en la Comunidad de Madrid $^{3}$, sobre todo los ecuatorianos y los rumanos, en general inmigrantes «económicos» que tienen como objetivo principal el trabajo ${ }^{4}$. Por ser la capital, por tener la economía muy dinámica, por abrirse al mundo mediante la puerta internacional del aeropuerto de Barajas, por ofrecer oportunidades singulares de vida y de empleo, la Comunidad de Madrid es el mayor punto de referencia de la inmigración.

Entre los colectivos más señalados, la inmigración procedente de América Latina es, sin duda alguna, la que tiene más tradición en la CAM, sobre todo, los ecuatorianos y los colombianos, inmigrantes analizados en este trabajo. El colectivo ecuatoriano, el de mayor número en los últimos seis años ${ }^{5}$, ha sufrido una ralentización en su crecimiento a partir del año 2003, en que empieza a exigirse visado a los nacionales de Ecuador. Según los Padrones de Habitantes de 2006 y 2007 ha disminuido la cifra oficial de los ecuatorianos y esta disminución puede traducir casos de ecuatorianos que han adquirido la nacionalidad española por residencia y de otros que han abandonado la $\mathrm{CAM}^{6}$, pero también existen personas que siguen viviendo en la Comunidad, pero sin renovar su empadronamiento. Es un colectivo joven, de carácter femenino, que ha reagrupado a sus familiares de forma rápida, siendo el volumen de niños y jóvenes el más destacado entre todos los inmigrantes de la CAM. El colectivo colombiano, a su vez, es contemporáneo al ecuatoriano, aunque su flujo no adquirió nunca las dimensiones del primero, y a partir de la exigencia de visado para

2 Entre 1998 y 2008 España recibió 4.500 .000 personas, de tal manera que en 2008 se llegó a 5.220.577 inmigrantes. Fuente INE, 2008.

3 En la Comunidad de Madrid trabajaban, a finales de 2008, 740.000 inmigrantes, lo que supone el $22 \%$ de trabajadores de la región.

4 Carrasco Carpio, 1998.

5 Jokisch y Pribilsky, 2002.

6 En Gómez Ciriaco, E. J. et al. (2007), se muestra cómo Madrid fue la primera Comunidad de acogida del flujo ecuatoriano a España, pero va perdiendo peso a favor de otras provincias. 
entrar como turistas, en 2002, su crecimiento ha sido reducido. Es una colonia con carácter femenino $(55,2 \%)$ y que está experimentando un ligero envejecimiento, y empiezan a tener un peso notable los adultos de entre cuarenta y cincuenta años. Con todo, en 2008 vivían en la CAM 145.352 ecuatorianos y 72.940 colombianos $^{7}$. Su distribución espacial abarca el área que incluye la ciudad de Madrid (un 72,7\% ecuatorianos y 53,5\% colombianos viven en la ciudad). Su localización es más concentrada en los distritos populares de la almendra (Centro, Tetuán, Arganzuela) y los obreros de la periferia próxima (Carabanchel, Puente de Vallecas, Latina, Ciudad Lineal). Sin embargo, su importante volumen en la región hace que, fuera de la ciudad, estén presentes en la mayor parte de los municipios, tanto de carácter residencial-industrial, el Corredor del Henares, la Corona Metropolitana Sur y, en menor medida, la Corona Metropolitana Norte y Oeste, con una extensión hacia la Sierra de Guadarrama. Esta distribución tiene relación con la conexión de la población ecuatoriana y colombiana con empleos en el sector servicios (comercio y hostelería) y de buena parte de las mujeres con el servicio doméstico y de atención a personas mayores y enfermos.

Si bien la investigación española sobre la inmigración económica procedente de América Latina, en el ámbito nacional ${ }^{8}$ y autonómico ${ }^{9}$, experimentó un importante auge en la última década, los aspectos que vinculan la formación al empleo inmigrante han sido escasamente estudiados y sólo de forma tangencial, al tratar la precariedad o la discriminación laboral de los inmigrantes ${ }^{10}$.

\section{OBJETIVOS Y METODOLOGÍA}

La realización de la investigación proporcionó la oportunidad de analizar la situación laboral de los inmigrantes «económicos» que tienen como objeti-

7 Observatorio de Inmigración y Ayuntamiento de Madrid (2008).

8 Existe una cierta tendencia a analizar los movimientos migratorios latinoamericanos en los últimos años a medida que se ha ido formando una comunidad muy numerosa. Pérez Carames, 2004. Arellano, 2004. Domingo, 2005. Gil y Domingo, 2007.

9 Entre los estudios que analizan la presencia latinoamericana en España. Agrela, 2002. Domingo y Houle, 2004. Colectivo IOÉ, 2005. Cachón, 2006. Pérez Infante, 2007. Izquierdo y Fernández, 2007. Tezanos, 2007, y en la CAM véase entre otros: Herranz Gómez, 1996. Colectivo IOÉ, 1999. Colectivo IOÉ, 2002. García Ballesteros, y Sanz Berzal, 2004. Cubillo, Tornos, Aparicio Gómez, y Fernández García, 2004. Colecctivo IOÉ y Gil, 2005. Cabo, 2006.

10 Entre los escasos estudios, destacan Setién y López, 2002. Cachón, 2003. Parella Rubio, 2003. Vallecillo, Gámez, 2004. Martínez Veiga, 2004. Morillas Gómez, 2007. Tezanos, 2007. Pajares, 2008. 
vo principal el trabajo. Además de estudiar las características socioeconómicas y su situación laboral antes de venir a España y durante su estancia en España, se ha investigado la relación entre su formación y la consecución de empleos en Madrid. Para ello se ha realizado una encuesta personalizada (Encuesta IFECAM) entre los «inmigrantes económicos» latinoamericanos más numerosos, los de Ecuador y Colombia, además de los rumanos y marroquíes, mediante un muestreo de conglomerados en dos etapas (barrios dentro de los municipios, estratificados en la ciudad, área metropolitana y demás municipios de la Comunidad de Madrid, e inmigrantes pertenecientes a la población de referencia).

Se realizaron 1.101 entrevistas, de las cuales 376 correspondieron a ecuatorianos y 244 a colombianos, un $56 \%$. El error de muestreo para la Comunidad de Madrid es $+/-2,8 \%$ para las estimaciones de porcentajes correspondientes a categorías igualmente probables $(\mathrm{p}=\mathrm{q}=50 \%)$ a un nivel de confianza del 95\%. El cuestionario contenía 47 preguntas, distribuidas en cinco bloques: características sociodemográficas, situación migratoria y laboral previa en el país de origen, el mercado laboral en España, la formación y empleo de los inmigrantes en la Comunidad de Madrid, y el acceso a los servicios sociales.

Se completó la toma de datos con entrevistas en profundidad y grupos de discusión. Se hicieron cuatro entrevistas a responsables de asociaciones de colombianos y ecuatorianos, y seis entrevistas más a los representantes en las áreas sociales de varias instituciones relacionadas con el empleo y la formación de los inmigrantes en la Comunidad de Madrid (ayuntamientos de Torrejón de Ardoz y Coslada, de Alcorcón, Móstoles y Fuenlabrada, y de Collado-Villaba). Se completaron con dos grupos de discusión a 16 inmigrantes ecuatorianos y colombianos, de acuerdo a criterios de género, estructura del hogar en Madrid, trayectoria laboral, y expectativas para la formación educativa y profesional para el empleo.

\section{LOS DESAJUSTES ENTRE LA FORMACIÓN Y EL EMPLEO DE LOS INMIGRANTES}

La inmigración, en el contexto del mercado laboral español, es un fenómeno que no se puede explicar sin poner en contacto a las dos partes implicadas en el proceso: (i) una sociedad receptora, que necesita mano de obra para realizar trabajos que sus ciudadanos ya no aceptan fácilmente y con dificultades de integrar la oferta y la demanda ${ }^{11}$, y (ii) unos grupos humanos

11 Balch, 2005. 
que se atreven a abandonar sus hogares, para progresar económicamente, aunque sea a costa de olvidarse de su formación profesional y de desempeñar trabajos precarios, de carácter temporal y poco cualificados, por debajo de su nivel de formación, como refieren diversos estudios existentes sobre los desajustes entre la formación de los inmigrantes y el empleo en España y su capacidad de adaptación al mercado español y su influencia en los trabajadores españoles ${ }^{12}$.

\section{¿Es el nivel de formación en el país de origen determinante?}

El nivel de estudios no sólo es un buen indicador de clase social, sino que es uno de los factores fundamentales para evaluar, posteriormente, la empleabilidad de los trabajadores inmigrantes latinoamericanos en Madrid. El nivel educativo alcanzado por los inmigrantes latinoamericanos, colombianos y ecuatorianos, presenta unos perfiles un tanto peculiares con situaciones muy diversas (gráfico 1), desde quienes llegan con estudios universitarios, hasta mujeres — madres muy jóvenes - con escaso nivel educativo, con al-

Gráfico 1. Estudios de mayor nivel REALIZAdos.

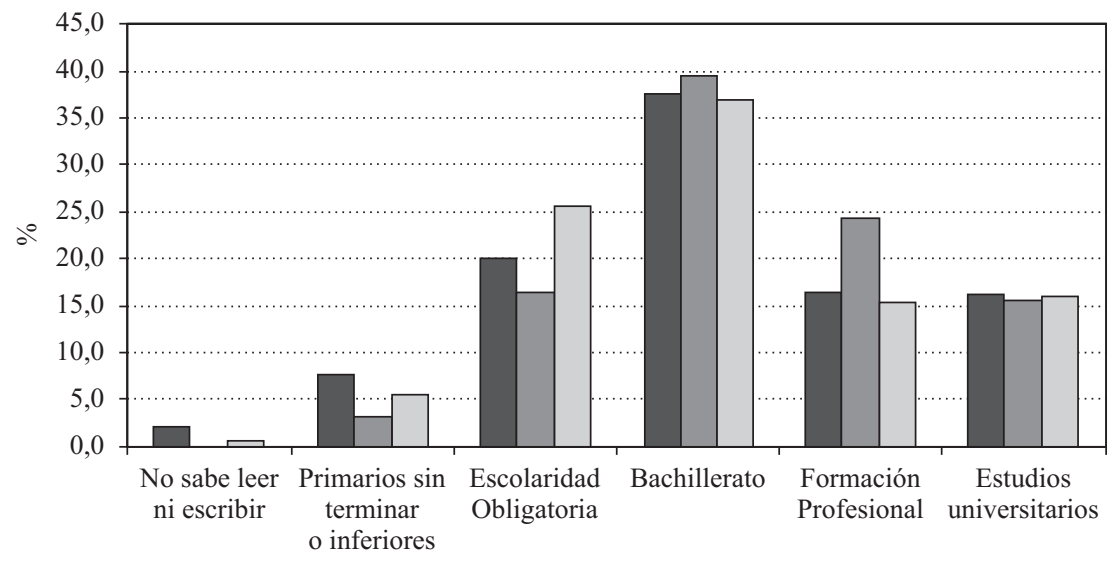

$\square$ Total $\square$ Colombia $\quad \square$ Ecuador

Fuente: IFECAM. Elaboración propia.

12 Véase Cachón, 2003. Carrasco y Ortega, 2005. Carrasco, Jimeno y Ortega, 2006. Amuedo y De la Rica, 2007. 
gunas diferencias por género no muy significativas. Casi un $40 \%$ tiene estudios de bachillerato, como nivel más destacado, siendo también importante el porcentaje de estudios de formación profesional (sobresaliendo los colombianos) y universitarios, y también la casi ausencia de inmigrantes analfabetos. Sólo los ecuatorianos parecen sobresalir entre los que han conseguido su nivel básico obligatorio. Tales niveles formativos deberían ser suficientes para favorecer el acceso de los inmigrantes latinoamericanos a determinados sectores productivos:

Mucha gente viene ya con su bachillerato terminado, y con carrera también, algunos han dejado la carrera a la mitad, otros la han terminado, pero el nivel de formación es alto, y no hay mucha diferencia de género (Asociación ACULCO Colombia).

El nivel de estudios del emigrante acá es muy bajo, es muy bajo, porque es gente que..., te hablo por gente allegada, gente que no tiene un buen nivel de educación, razón por la cual no puede estar en un buen trabajo (Asociación Red Integración Multicultural, Ecuador).

Son trabajadores mejor formados que sus padres (gráfico 2), portadores de estudios primarios, básicos y de bachillerato, no así de formación de carácter técnico o universitario. Es, por tanto, una inmigración económica de clases medias, mejor instruidas (bachillerato, formación profesional, universitaria), que no encuentran en sus países de origen unas oportunidades acordes a unas

GrÁFico 2. Estudios DE MAYOR NIVEL REALIZAdOS POR EL PADRE.

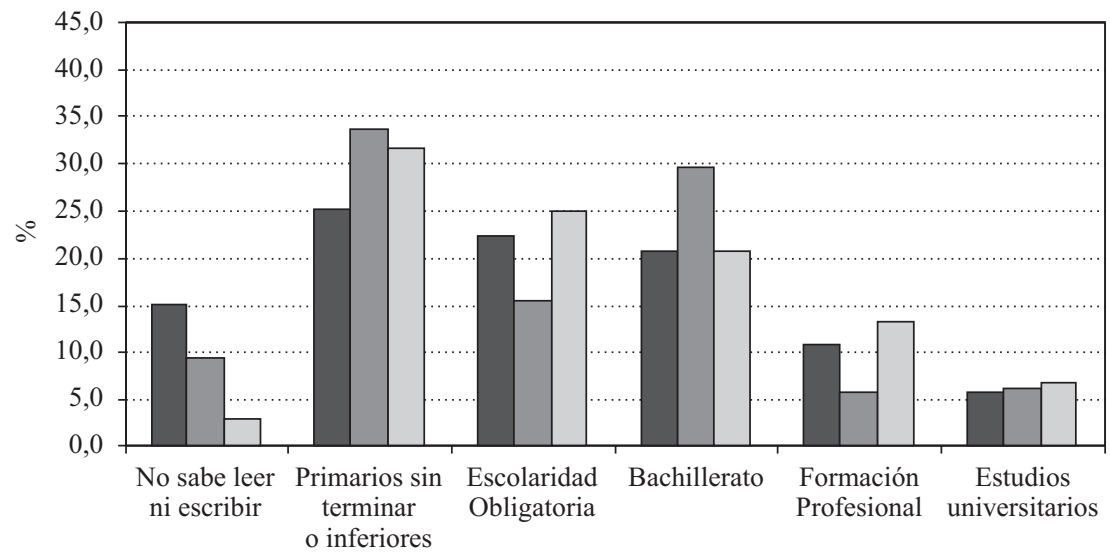

$\square$ Total $\square$ Colombia $\square$ Ecuador

Fuente: IFECAM. Elaboración propia. 
expectativas y formaciones, a pesar de haber conseguido ya una movilidad social (educativa) ascendente pero que tienen que salir de su país para intentar materializar sus oportunidades. Llegan a Madrid con la idea de obtener unos salarios mejores, desarrollando actividades de rango equiparable a sus capacitaciones. Pero se encuentran con que sus percepciones sobre las posibilidades de acceso a empleos adecuados a su formación estaban muy distorsionadas, enfrentándose a su llegada con la dura realidad de unas opciones laborales muy limitadas a empleos descualificados en ciertos sectores del mercado (construcción, servicio doméstico).

A ello se añaden otros factores que retardan su inserción en el mercado de trabajo madrileño, como la condición jurídica irregular, los estereotipos negativos y los prejuicios o las situaciones de pobreza y marginación social que se puedan presentar. Tampoco es de menor importancia la dificultad de homologar sus estudios y de reconocimiento de sus titulaciones, bien sea porque no se les convalidan, o porque no traen de sus países toda la documentación necesaria para conseguirlo, como instrumento esencial para el acceso a los empleos no tan precarios y mejor considerados:

También hay dificultades grandes con la homologación porque hay carreras que no se pueden homologar, desafortunadamente, ¿no?, Eso también influye en el retroceso... de personas que teniendo una licenciatura, han hecho aquí un máster y luego han visto que no les han convalidado (Asociación Candelita, Colombia).

Sin embargo, aun con la homologación, permanecen actitudes entre empleadores y colegios profesionales para minusvalorar las titulaciones, en la creencia que el sistema educativo reglado de esos países no tiene la calidad del sistema español.

\section{¿Es posible superar la contradicción entre una formación conseguida y un empleo no adaptado a la misma?}

La relación entre el nivel de formación y la posibilidad de encontrar un empleo es un problema que sigue sin resolverse no sólo en el caso de los inmigrantes, sino también para los españoles, sobre todo para los jóvenes ${ }^{13}$.

13 El informe Cifras clave de la educación en Europa 2005 (Eurydice, Red Europea de Información en Educación) asegura que sólo el 40\% de los titulados universitarios tiene en España un trabajo acorde a su nivel de formación, al nivel de Francia y Chipre en la UE. Y eso que la elevada tasa de paro que se registra en la Europa de los 25 impide que la cifra de los universitarios que ocupan un puesto de trabajo de nivel superior o una profesión intelectual supere el $50 \%$. 
Ello es también apreciable en la Comunidad de Madrid. Como bien es sabido, el acceso al trabajo es el elemento clave para el éxito de la integración. Para los inmigrantes, el trabajo puede convertirse en un factor de exclusión cuando se les somete a condiciones laborales de discriminación o segregación específicas, lo que tiende a suceder en el mercado laboral secundario. Esas situaciones pueden documentarse al valorar la diferencia entre los empleos detentados antes de salir de su país y los conseguidos en Madrid para el mismo nivel formativo.

Se puede afirmar que esta adecuación ya viene viciada desde el país de origen desde el momento en que casi el 30\% de los ecuatorianos y un 16\% de los colombianos encuestados afirman ya estar más cualificados para el trabajo que desempeñaban en su país antes de venir a Madrid (escasamente un 1\% afirman tener la situación contraria). Ello puede significar que ya la estructura del mercado de trabajo en su país no era capaz de soportar sus expectativas y que tal pensamiento puede estar motivando la decisión de buscar mejores expectativas en Madrid. La situación laboral en que se encontraban los ecuatorianos y colombianos antes de emigrar a Madrid es expresiva de una cierta precariedad: sólo algo más del $40 \%$ de los encuestados aseguran tener un empleo fijo o ser empresarios o trabajador autónomo, mientras un $29 \%$ de los colombianos y un $35 \%$ de los ecuatorianos tenían una situación "precaria» (empleo eventual o por horas o no tenían contrato o lo tenían sólo de forma verbal, o eran miembros de la familia que ayudaban al negocio propio). El resto, aproximadamente uno de cada cuatro, no están en el «mercado» (parados, estudiantes, jubilados, amas de casa).

En estas condiciones ni la formación educativa ni el propio mercado son capaces de retener a los inmigrantes. La migración tampoco parece la solución definitiva. Los cambios que se esperan pueden no ser en muchos casos los que se consiguen. Un valoración de los cambios acaecidos entre el empleo detentado en su país de origen y en Madrid, después de haber emigrado, es sintomática de una realidad de múltiples facetas. A partir de la revisión del sector de actividad en la que los colombianos y ecuatorianos trabajaban en su país, antes de emigrar, y en Madrid se detectan dos situaciones básicas (gráficos 3 y 4): unos sectores incrementan el porcentaje de trabajadores en el proceso de asentamiento de los inmigrantes en Madrid, en otros se presenta la situación contraria. El cambio de actividad en el proceso migratorio parece ser una transición del sueño a la realidad. Conviene hacer el análisis de esta situación tomando en cuenta algunas trayectorias laborales de notable valor.

Los sectores de actividad en los que preferentemente trabajaban en su país los inmigrantes latinoamericanos, en porcentaje superior al $15 \%$ del total de 
GrÁFICO 3. VARIACIÓN DEL EMPLEO DE LOS INMIGRANTES COLOMBIANOS.
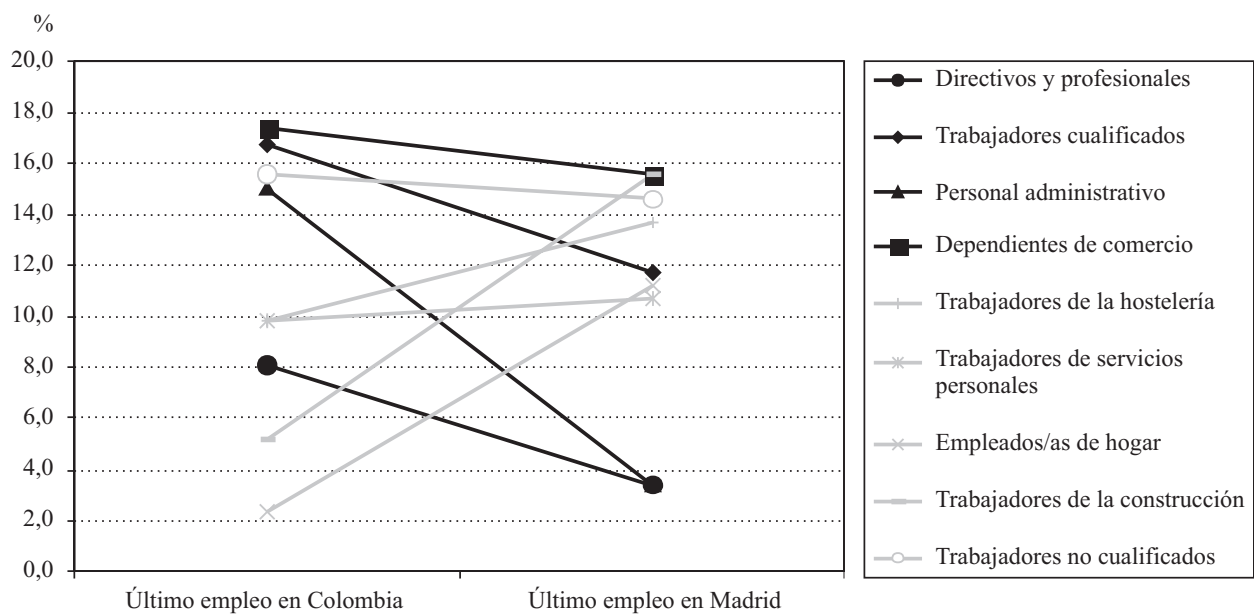

GrÁFICO 4. VARIACIÓN DEL EMPLEO DE LOS INMIGRANTES ECUATORIANOS.
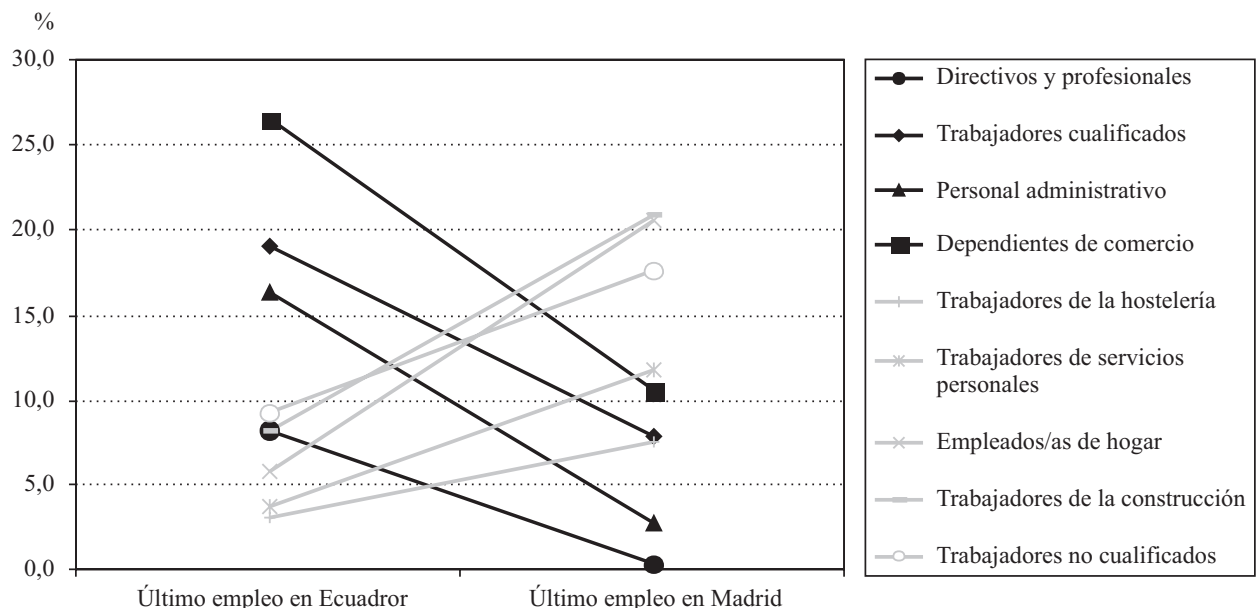

Último empleo en Ecuadror

Último empleo en Madrid

Fuente: IFECAM. Elaboración propia.

los inmigrantes encuestados, son básicamente terciarios de un cierto nivel de cualificación, como los dependientes de comercio o los empleados en servicios administrativo, o siendo trabajadores cualificados en determinados secto- 
res industriales: trabajadores cualificados de industrias extractivas y metalúrgicas, trabajadores cualificados de industrias de artes gráficas. En mucha menor proporción son profesionales de la enseñanza o de la salud. No hay que perder de vista el hecho de que los profesionales y directivos, los administrativos y los trabajadores cualificados solían tener un contrato fijo en su país (no en el caso de los dependientes de comercio) como situación laboral dominante lo que refleja un cierto nivel de precariedad en sus expectativas laborales futuras. Pero tampoco en Madrid van a encontrar empleos como los que tenían en su país, en tanta proporción.

En general, son experiencias de movilidad descendente, que ponen de manifiesto los desajustes entre la formación y el empleo que desarrollan los inmigrantes latinoamericanos en la Comunidad de Madrid, aunque no se refieran a grandes números de acuerdo al tamaño de la población investigada. Al llegar a Madrid, la principal y casi única vía de entrada al empleo es el trabajo precario y poco cualificado: una parte reducida de estos trabajadores administrativos, profesionales y empleados de comercio su ubican en el mismo sector, pero la mayor parte se dedican a trabajo temporal y eventuales en la construcción y el comercio y la hostelería para los hombres, y servicio doméstico interno/externo y otras actividades de atención personal para las mujeres.

El acceso a un empleo permite garantizar la manutención, la obtención de rentas para solventar determinadas urgencias económicas adquiridas, por ejemplo, los gastos de viaje, y la posibilidad de conseguir o mantener en el futuro un permiso de trabajo. A cambio se encuentra un contexto laboral que choca profundamente con la experiencia anterior: de una ocupación con un cierto estatus se pasa a una situación más o menos vergonzante. Particularmente duro es el tránsito para las mujeres licenciadas universitarias, que se emplean como internas puesto que pasan de cumplir una función cualificada a ser mandadas por todo el mundo, incluidos los niños de la casa y, especialmente, dejan de actuar en la esfera pública y quedan recluidas en un ámbito privado, con escasas posibilidades de establecer relaciones personales y afectivas.

Este perfil de inmigrantes con estudios muestra notables niveles de decepción y malestar personal, una vez que sus ilusorias representaciones iniciales han sido refutadas de forma abrupta por su problemática inserción en el mercado de trabajo, en la realidad socioeconómica de Madrid. La condición de irregular que tienen muchos inmigrantes, incluso, tras algunos años en España, en la Comunidad de Madrid, contribuye mucho al retroceso que se observa en su trayectoria laboral:

... Aquí te condiciona mucho la cuestión de la legalidad, de todo lo que se refiere a si eres informático o ingeniero o abogado, para que tú puedas trabajar en tu campo se requiere que tengas los papeles en regla... porque conozco mucha gente 
que viene con sus carreras ya, su formación completa y aquí como no tienen los documentos comienzan a trabajar en hostelería, en una parte en otra y ya se quedan ahí, me parece interesante lo que ahorita pase y dentro de unos meses la gente que se está regularizando, que tiene su carrera, que tiene formación, que ellos tienen acceso al mercado laboral en otros sectores si la preparación es buena, claro... (Grupo de discusión. Hombres, Colombia y Ecuador).

De esta forma, entre su preparación y empleo que están obligados a asumir para sobrevivir, no sólo no existe congruencia, sino tampoco continuidad. Es un inmenso desajuste, y, además, un retroceso:

En cuanto a mejora o retroceso, casi hay un retroceso en esos primeros años de emigración ¿no? por el problema de identidad por el que hay que pasar, casi se estanca un poco porque, además, como el nivel de trabajo al que tienes que acceder, no tiene que ver con tu nivel intelectual o de formación profesional, pues ahí hay un pequeño... (Asociación Candelita, Colombia).

Ante esta realidad surgen, como reacciones, no sólo la represión de sus inclinaciones, sino también un fuerte sentimiento de marginación social, de incomprensión por parte de la sociedad de acogida, lo que, a veces, provoca un sentimiento de alienación y, muchas veces, de confrontación:

Luego, una vez dentro de que están en la construcción, hay muchos que si se han interesado, y, es decir, ya una vez que tienen que estar allí pues pueden aprender carpintería, fontanería, para ir subiendo dentro del trabajo que han tenido que empezar de cero, olvidándose muchas veces, de toda la formación universitaria recibida en Ecuador,... pues al final terminan perdiéndose mucho y desconectándose (Asociación Fundación Alianza, Ecuador).

Por otro lado, son muchos menos numerosos entre los inmigrantes latinoamericanos que llegaron a Madrid los trabajadores no cualificados (no en el caso de Colombia), los empleados de hogar, de servicios personales, de hostelería y de la construcción, pero van a ser estos sectores de la economía madrileña los que van a atraer a mayor cantidad de trabajadores inmigrantes, independientemente de cuál fuera la actividad laboral desempeñada en su país. Y es que su situación en su país era claramente precaria (trabajando por horas, de forma eventual o incluso con contratos verbales).

Una segunda trayectoria es el descenso leve del estatus ocupacional del país de origen, pero con ingresos mayores (gráficos 3 y 4). Tal como se aprecia tras el análisis, una buena parte de los inmigrantes proceden de estratos económicos medios, o medio-bajos, y han desarrollado una actividad laboral en su país de origen antes de emigrar. Frecuentemente, han trabajado, como trabajadores no cualificados en la construcción, en la hostelería, como empleados de hogar y como dependientes de pequeños comercios, como es el caso de los trabajadores no cualificados colombianos o los de la hostelería, procedentes de Ecuador. Mu- 
chos de ellos, en realidad son más mujeres que hombres, pasan a desempeñar trabajos de semejante cualificación, por lo que, desde el punto de vista del estatus sociolaboral, no se producen cambios significativos al llegar a Madrid, pero el nivel salarial sube, lo que permite en poco tiempo saldar las deudas del viaje y comenzar a enviar remesas a la familia en el país de origen. Este hecho ya es en sí una diferencia positiva y más importante como inmigrantes:

... Aquí hay gente que viene de allá, que son albañiles, hablando de los hombres, saben de albañilería y vienen de aquí y ellos están muy bien; ellos no piensan volver porque dicen que aquí ganan muy bien y están en una situación económica muy buena... (Grupo de discusión. Mujeres, Colombia y Ecuador).

Entre los trabajadores ecuatorianos empleados en el sector de la construcción con una cierta cualificación en Madrid, 61 en la encuesta, más de una cuarta parte provienen del mismo sector en Ecuador, aunque es posible que con un nivel de cualificación no equiparable, siendo el resto otros trabajadores cualificados de la industria y empleados de comercio. La relativa pérdida de cualificación se ve compensada por un mayor salario que en su país. De la misma manera, de los 56 empleados/as de hogar ecuatorianas en Madrid que fueron encuestados/as, sólo siete provenían de la misma actividad en su país, siendo el resto empleados del comercio y administrativos. Semejante es la situación de los trabajadores no cualificados colombianos en Madrid que antes estuvieron trabajando en el comercio, como administrativos o en servicios personales.

En tercer lugar, es posible detectar mecanismos que implican un relativo ascenso, mediante el paso de actividades eventuales al empleo asalariado. Se trata de las personas que salen de su país sin experiencia laboral. En este caso el acceso a un empleo y la disponibilidad de unas rentas salariales suponen una trayectoria ascendente, al menos desde la perspectiva personal del inmigrante:

«Pues como decíamos depende de la formación, hay gente, hay mucha gente que me cuenta que en su país estaban haciendo lo que podían, como dicen ellos, porque como no hay trabajo hacían lo que les iba saliendo, entonces normalmente son trabajos manuales lo que hacían también» (Ayuntamiento de Torrejón de Ardoz).

Es importante señalar que, aunque el estatus familiar de origen sea superior al que brinda la nueva inserción laboral, no cabe catalogar esta trayectoria como descendente puesto que la movilidad espacial (la migración) permite incorporarse al mundo laboral y establecer el punto de partida para una eventual trayectoria económica autónoma respecto a la familia paterna. En ocasiones la emigración facilita el tránsito al mundo del trabajo, debido a que la debilidad 
de los lazos de control y prestigio social, permiten aceptar empleos que en su propio país rechazarían debido a su baja consideración social. En este caso, los inmigrantes necesitan adecuar su formación a la actividad que desempeñan, porque existe muy a menudo la situación en la que se posee una cualificación superior a la media de los sectores de construcción, de restauración. Se trata de una «anomalía», puesto que las expectativas sociales de los inmigrantes en sus países de origen no se formaron en función de un trabajo manual poco cualificado e inestable, lo que se necesita corregir mediante una formación adecuada.

Algunos factores pueden ayudar a entender los desajustes entre la formación disponible y los empleos conseguidos en la Comunidad de Madrid (gráfico 5). El más destacado, sin duda, es el que tiene que ver con el cumplimiento de condiciones jurídicas para el desempeño de empleos. Son frecuentes las referencias a la situación de ilegalidad en la que muchos inmigrantes se encuentran (en torno a un $80 \%$ de los colombianos y ecuatorianos así lo reflejan), a las dificultades de los inmigrantes no comunitarios para acceder a determinados empleos vinculados a la pertenencia a la Unión Europea, y a las limitaciones para la homologación de los títulos obtenidos en los países de origen. Estos hechos crean, obviamente, mucha frustración entre los inmigrantes. Otro factor no menos importante está vinculado a los prejuicios sociales acerca de la formación y las capacidades profesionales de los inmigrantes. Se tiene una imagen estereotipada según la cual, los inmigrantes no comunitarios tienen es-

Gráfico 5. Principales dificultades para encontrar trabajo cUando lo ha buscado.

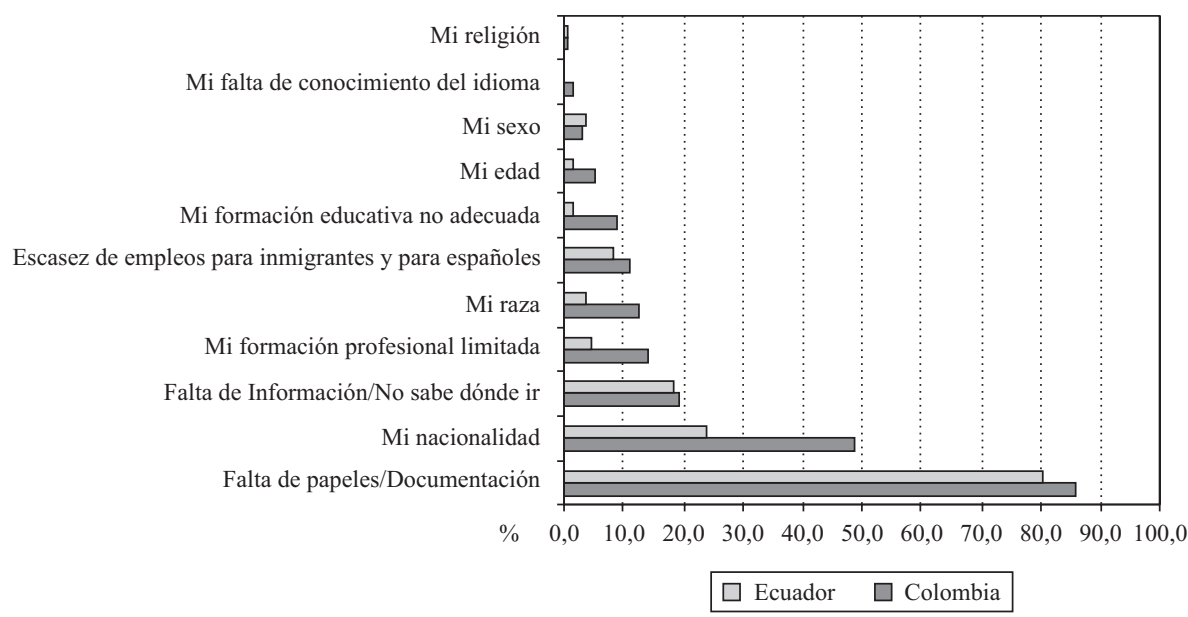

Fuente: IFECAM. Elaboración propia. 
casa formación, algo que aumenta en la medida en la que las distintas generaciones de la población autóctona los ve empleándose en trabajos de escasa cualificación. La formación aparece referida como factor limitante entre un $15 \%$ y un $20 \%$ de los inmigrantes latinoamericanos encuestados. A ello contribuye el que se trate de una inmigración joven, en su mayor parte, en España (una media de cinco años), personas que todavía pueden no haber acabado su ciclo formativo, y que lo podrá hacer aquí, en la Comunidad de Madrid, mediante cursos, para insertarse en el mercado laboral, y reducir estos prejuicios sociales. Pero no cabe duda de que, aun así, el nivel educativo de la población inmigrante es superior al que corresponde con los trabajos que está realizando, y que los prejuicios sociales contribuyen a situarles dentro de estos nichos laborales.

Cercano al anterior habría que señalar la discriminación directa en el acceso al empleo, que, aunque se registra cada vez menos, sigue existiendo en algunos sectores de actividad de la Comunidad de Madrid, cuando el empleador o empresario decide no contratar a una persona por el hecho de que sea de un determinado origen, que tenga unos rasgos específicos, o, sencillamente, un acento diferente al hablar el castellano. La nacionalidad, de forma desigual, aparece destacada entre las dificultades de estos inmigrantes a la hora de buscar empleo. ¿Por qué sólo en algunos sectores? Porque en los sectores laborales y categorías en los que se concentra la inmigración económica, los inmigrantes no sólo no son rechazados, sino que a veces, incluso son preferidos independientemente de cualquier situación personal o incluso administrativa. Pero en lo que llamamos el mercado primario, se observa esta discriminación señalada:

... tienes que ser necesariamente español, y volvemos a lo mismo eso es, esos mecanismos que no ayudan a que se aproveche a la gente profesional que ya si ha invertido... (Asociación Candelita, Colombia).

No obstante, no es una tendencia muy extendida el que los inmigrantes latinoamericanos encuentren diversas formas de discriminación en las relaciones laborales (gráfico 6). Son, en efecto, más numerosos los trabajadores latinoamericanos que refieren actitudes positivas derivadas de su vinculación laboral, tanto en sentido económico como social y personal, especialmente entre los ecuatorianos. Por el contrario, las actitudes negativas, incluso vejatorias contra la condición humana, son referidas en mucha menor proporción, si bien tiende a aparecer una imagen negativa entre los colombianos, en comparación con los ecuatorianos, desde el momento en que los primeros manifiestan sufrir «desconfianza», o incluso «desprecio» o «insultos», probablemente actitudes derivadas de la «imagen social» del país que influyen en la condición de trabajadores. 
GrÁFICO 6. ACTITUDES EXPERIMENTADAS POR LOS INMIGRANTES DE SUS EMPLEADORES.

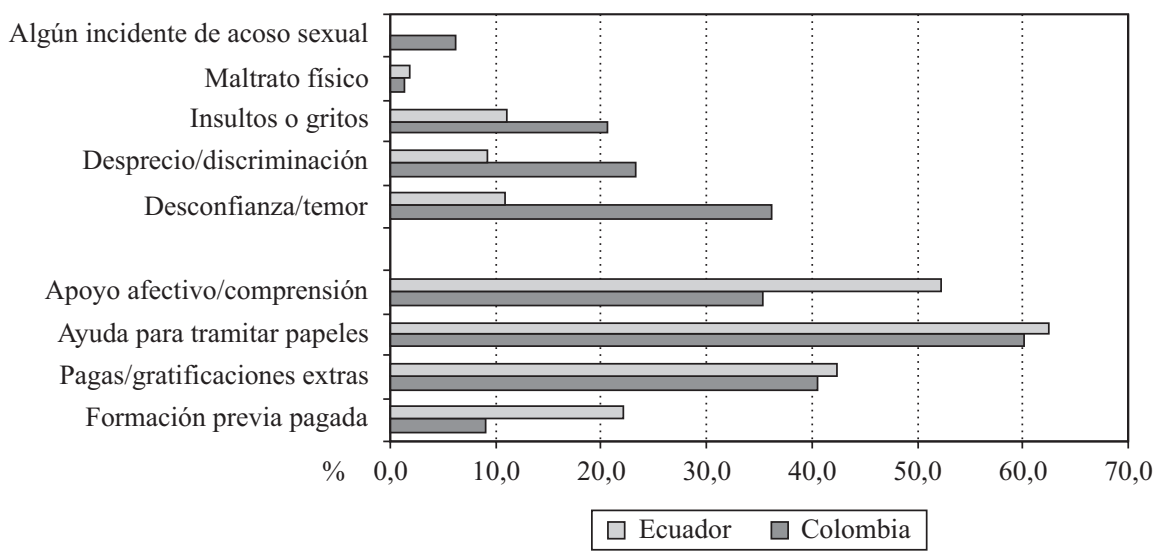

Fuente: IFECAM. Elaboración propia.

El propio acceso al empleo por parte de los inmigrantes es otro factor limitante. La mayor parte de los inmigrantes buscan empleo a través de las redes étnicas, se colocan en su primer o segundo empleo en la Comunidad de Madrid mediante familiares y amigos de la misma nacionalidad, sin buscar realmente un trabajo por sí mismos. Se trata de redes sociales por las que circulan informaciones sobre empleos, y ello favorece que el empleo se encuentre en los mismos sectores, en los que hay inmigrantes del mismo país. El 67\% de los ecuatorianos encuestados y el $72 \%$ de los colombianos refieren haber encontrado su trabajo a través de familiares, amigos de su país o españoles. El encapsulamiento del inmigrante en su red social no facilita el relacionarse con las estructuras propias del mercado de trabajo. De esta manera, se ha creado una imagen, según la cual los hombres latinoamericanos, no importa si en origen fueran ingenieros o trabajadores en la industria pesada, tienden a trabajar en Madrid en construcción, y las mujeres, algunas licenciadas, en servicio doméstico:

Yo creo que deberían reconocer más a la gente que viene, que ha estudiado y tiene sus títulos y no, por ser emigrante y por eso... sí facilitar esos movimientos, esas cosas que ya lo hemos estudiado, sí, sí de profesionales que vienen de estos países; porque la mayoría de gente que hemos llegado, no son personas que no tienen, yo pienso que si se puede hacer un censo, la gran mayoría son profesionales (Grupo de discusión. Mujeres, Colombia y Ecuador).

¿Es posible salir de los nichos laborales y mejorar las condiciones de acceso al empleo? La llegada a Madrid y la inserción en el mercado laboral repre- 
sentan, casi en todos los casos, un choque para los inmigrantes, ya que su margen de maniobra es estrecho a la hora de desplegar sus estrategias de inserción. Se decantan primero por aceptar las primeras oportunidades que se presentan, para luego, una vez garantizada la supervivencia inmediata, comenzar a captar las claves del nuevo entorno, comparar posibilidades, establecer nuevas relaciones y desplegar estrategias en función de las expectativas de los inmigrantes.

El que los inmigrantes se empleen en mayor número en el servicio doméstico, la construcción y la hostelería no significa que no puedan estar interesados en nuevos sectores laborales, a pesar de las dificultades originadas por disponer de permiso de trabajo temporal para un determinado sector de actividad. En otros casos es posible modificar su situación laboral de asalariado en autónomo, lo que consiguen sobre todo los inmigrantes con experiencia profesional, que llevan más tiempo de residencia en España, que tienen documentación en regla y ahorros:

... Hombre, es complicado porque tendrías que tener un tanto de ahorro para montar la empresa, porque no es que voy con mis papeles y ya me dan la papeleta, ya es autónomo y vete a trabajar; primero tenéis que tener algo ahorrado y después de eso tener los contactos; si eres albañil y te montas una empresa de albañilería, tendrías que haber tenido antes contactos para que te llame uno u otro, y así sigues trabajando... (Grupo de discusión. Hombres, Colombia y Ecuador).

En general, se puede afirmar que, de acuerdo a sus opiniones, su trayectoria laboral desde que viven en España ha mejorado en casi el 80\% de los colombianos y el 55\% de los ecuatorianos encuestados. Es la respuesta previsible a la mejora de su situación personal y laboral, ligada a un período de estancia en Madrid ya alto, más allá de las opiniones personal ligadas a aspectos concretos de sus relaciones laborales.

\section{LA MEJORA EN EL NIVEL FORMATIVO COMO REQUISITO PARA LA MEJORA EN EL EMPLEO}

Admitidas las limitaciones de los inmigrantes para acceder al mercado de trabajo en Madrid, debido al desajuste entre su formación educativa y la demanda de empleo regional y local, y conocidas las dificultades que impone el mercado de trabajo madrileño para los inmigrantes en general, y los latinoamericanos en particular por su conocimiento del español, la oferta de cursos de formación para el empleo aparece como un requisito esencial para superar esas limitaciones. 


\section{¿Cuáles son las condiciones para la formación para el empleo de los inmigrantes?}

La oferta de formación, pública y privada, para la mejora del empleo es un hecho, en general, bastante desconocido entre los inmigrantes.

Apenas 31 colombianos y 23 ecuatorianos entrevistados declaran haber realizado cursos de formación para el empleo, apenas un 13\% y $6 \%$ respectivamente. La inmediata consecuencia es que, previsiblemente, estos inmigrantes no tienen demasiado interés por explorar esta vía, la de realizar cursos, como modo de asentar unas mejores condiciones laborales en la Comunidad de Madrid, debido a sus rasgos sociodemográficos. La edad parece favorecer el que se hagan cursos entre los más jóvenes, con edades de 35 a 44 años, pero esta tendencia se desacelera, lógicamente, cuando aumenta más la edad. Es de esperar una relación entre la realización de cursos y el más elevado nivel educativo de base: de entre los encuestados que afirman haber hecho cursos de formación cuando trabajan en la Comunidad de Madrid casi un $80 \%$ han terminado estudios de bachillerato, formación profesional y estudios universitarios, un $36 \%$ en este último caso. Es previsible que el tiempo de estancia aumente las posibilidades de mejora y estabilización de las condiciones laborales de los inmigrantes, y ello haga aumentar las posibilidades de realizar cursos: conociendo que el valor medio de estancia en Madrid apenas supera, entre los inmigrantes latinoamericanos encuestados, los tres años, el porcentaje de los que afirman realizar cursos casi se duplica en el caso de los que llevan más de cinco años $(13 \%)$ en relación con los recién llegados.

Cifras tan bajas de población inmigrante que hace cursos obligan a preguntarse sobre su grado de conocimiento de la oferta de cursos en la Comunidad de Madrid, diferenciando también los que se hacen en el municipio en el que residen. Cuando se les ha preguntado acerca de su grado de conocimiento de los cursos de formación se han detectado algunos hechos de enorme significado. La conveniencia y el interés por obtener valor añadido de la formación para el empleo se ve por las estrategias puestas en el proyecto migratorio: más del 70\% de los inmigrantes latinoamericanos aprecian la valía de este camino para conseguir una mejor accesibilidad al trabajo a través de la formación, especialmente los que tienen más déficit formativos para el tipo de empleo que se demanda en la Comunidad de Madrid.

Las razones aducidas por los encuestados para no hacer cursos de formación tienen que ver con una cierta «descolocación» de los inmigrantes en la sociedad madrileña, que ni siquiera las asociaciones consiguen corregir en muchos casos, quizás porque éstos no se interesan en la información cuando se les ofrece: 
... aquí hay gente que pasa un día y ve la cartelera donde están los cursos, pero, no le llega a toda la población, no le llega a toda la población ¿por qué?, porque es una población que desconoce mucho las oportunidades que efectivamente tienen (Asociación ACULCO, Colombia).

O con la falta de sintonía que hay entre la oferta, generalista para un conjunto personas y situaciones, y la demanda específica de los inmigrantes, por sus prioridades o la falta de interés de algunos grupos (los jóvenes, cuando no tienen otra actividad mejor que hacer cuando están en paro):

... no tengo nada que hacer, me apunto, porque no está arreglado, con lo cual algo ganaré, o chavales jóvenes, chavales jóvenes que ahora mismo, bueno, no tengan nada entre manos y digan, bueno, pues me puedo apuntar, por lo menos hecho el currículum y no pierdo nada (Ayuntamiento de Móstoles).

Hay, sin embargo, grandes dificultades para no hacer cursos, derivadas de la situación de los trabajadores inmigrantes latinoamericanos para favorecerse de los recursos disponibles para mejorar su formación para el empleo. La posición de los inmigrantes en el mercado de trabajo de la Comunidad de Madrid es harto difícil en sus rasgos principales, inestable en la secuencia temporal y limitada en sus expectativas, al menos en los primeros momentos. Condiciones laborales poco estables, inseguridad en el puesto de trabajo, precariedad en las condiciones de trabajo, etc., son elementos definitorios de su estatus que no facilitan la disponibilidad de tiempo para otras actividades, laborales, sociales, familiares o personales, más allá del tiempo de trabajo excesivo que haga más fácil la obtención de recursos económicos para vivir en Madrid:

Creo que hay poco tiempo para mirar periódicos, Internet, y ver qué cursos de formación hay, y luego claro, es como todo, cursos de formación que sean compatibles con tu trabajo, es decir, cursos de formación para superarte, y si yo trabajo de ocho de la mañana a ocho de la tarde, difícil...(Ayuntamiento de Móstoles)

...uno el horario que a veces prestan estos cursos que no es compatible con las actividades que uno hace, porque no va a dejar de trabajar para hacerte un curso ¿no?, aparte también, donde están ubicados, la ubicación. Si tú, por más que te den un curso excelente, pero si te toca dos horas de donde tú vives, imposible (Asociación Red de Integración Multicultural, Ecuador).

No es de extrañar por ello que la principal razón aducida por los inmigrantes para no hacer cursos de formación sea la imposibilidad física derivada de la no disponibilidad de tiempo adecuado para ello, en relación con el excesivo tiempo de trabajo, especialmente entre los colombianos (gráfico 7).

A pesar de estas dificultades inherentes a un mercado de trabajo precario y limitado para los inmigrantes, la flexibilidad para realizar cursos es entendida como una solución que sólo aparece cuando el promotor del curso es una asociación o departamento de servicios sociales del ayuntamiento, pero no si los 
GrÁFICO 7. RAZONES DE LOS INMIGRANTES LATINOAMERICANSO PARA NO HACER CURSOS DE FORMACIÓN.

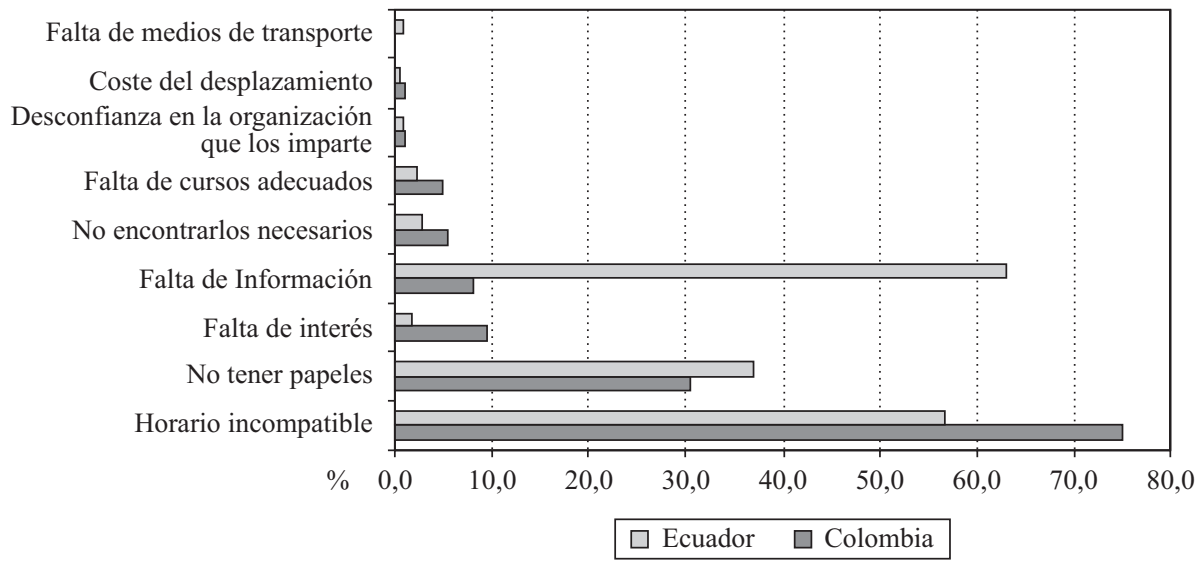

Fuente: IFECAM. Elaboración propia.

cursos son impartidos por otras instituciones, apegadas a una reglamentación horaria más estricta:

... yo creo que los sábados es un día clave para dar cursos, el sábado, nosotros lo hacemos el sábado, lo hemos hecho siempre, porque sabemos que va mas gente, que va muchísima gente también que lo pide... (Asociación ACULCO, Colombia).

Un segundo problema, el no disponer de papeles, se deriva de otro hecho consustancial con los inmigrantes latinoamericanos y su forma de llegar a España, generalmente como turista, sin papeles adecuados para una estancia más duradera y orientada a la consecución de un empleo. La vida de inmigrante sin papeles se demuestra posible en Madrid; en cambio, la vida como inmigrante trabajador, aunque posible, se ve limitada en muchas de sus facetas. Una de las ellas sin duda es su limitación para hacer cursos, toda vez que el requisito básico para solicitarlos es tener una situación legal como trabajador en España, con permiso de trabajo y residencia y estar inscrito en el INEM o Servicio Regional de Empleo, en caso de trabajador desempleado, requisitos que muchos de ellos, en algún momento de su estancia, no pueden cumplir. Inevitablemente la supervivencia del inmigrante le obliga a la búsqueda inmediata de trabajo, necesaria para la persona o familia, pero reñida con la conveniencia de su formación; la segunda puede esperar, la primera es perentoria. Esta situación, como otras que afectan a los inmigrantes en España, tiene esa doble dimensión que hace que las instituciones oficiales la vean como una norma ba- 
sada en el principio de legalidad - la equiparación de derechos de los trabajadores, inmigrantes o no, en su acceso a los recursos públicos- mientras que los inmigrantes, y en muchos casos sus asociaciones, la valoren como el peaje a pagar por incorporarse a la sociedad de acogida, lo cual, en su opinión, les deja en una situación postergada, cuando no de discriminación:

... si es gente sin documentación no pueden acceder a los cursos porque las personas que hacen los cursos tienen justificar esas plazas con la tarjeta del INEM (Ayuntamiento de Torrejón).

... que si no estás adscrito al INEM, entonces no los puedes hacer, una contradicción no, eso no es una contradicción, es una dificultad, para las personas emigrantes que quieren formarse, que quieren hacer un progreso a nivel, digamos, de su formación laboral (Asociación Candelita, Colombia).

Otra razón es su falta de conocimiento de la oferta institucional de cursos de formación, hecho en el que inciden las múltiples dificultades que como inmigrantes tienen para captar las posibilidades del entorno social, económico e institucional en Madrid. Los ecuatorianos, en razón del escaso tiempo de vida como inmigrantes en Madrid y el alto ritmo de llegada en los últimos años, parecen encontrarse en una posición más dificultosa, que, sin duda, se irá atenuando en los próximos meses, una vez entren en funcionamiento los instrumentos y comportamientos de autoayuda dentro de su comunidad y desarrollen los medios de capital social que hagan más fácil su acceso a los recursos institucionales disponibles.

\section{¿Son los cursos útiles para los inmigrantes latinoamericanos?}

A pesar de que son pocos los inmigrantes colombianos y ecuatorianos que hacen cursos de formación en Madrid, éstos han manifestado la validez y utilidad de la apuesta formativa que tomaron tanto en referencia al momento de buscar trabajo, como a las posibilidades que los cursos abren para el futuro de su actividad laboral. Las opiniones y porcentajes varían entre una nacionalidad y otra, pero se decantan hacia aspectos positivos como la «apertura de nuevas posibilidades de empleo» ( $37 \%$ de los colombianos, $53 \%$ de los ecuatorianos), la «mejora de las expectativas laborales» (55\% de los colombianos), la posibilidad de «completar la formación» (63\% y 37\%, respectivamente), o el «establecimiento de contactos con el mercado de trabajo» (29\% de los ecuatorianos). En definitiva, el simple hecho de tener acceso a cursos con una notable carga formativa sin más coste para el inmigrante que el tiempo empleado en las clases es valorado muy positivamente:

... eso de tener una formación con doscientas horas así que no les cueste y que te consigan un título de ayudante de no sé qué o auxiliar de no sé cuál, pues les parece como muy gratificante... (Ayuntamiento de Torrejón de Ardoz). 
Sin embargo, los problemas percibidos al recibir los cursos de formación son limitados, en buena medida, a las condiciones de acceso personal cuando se tienen condiciones difíciles, inestables y precarias, para desempeñar un puesto de trabajo (un 17\% así lo manifiestan) o cuando el coste del desplazamiento desde el lugar de residencia o trabajo al centro donde se imparte el curso es alto y no encaja en el horario y en la economía del trabajador inmigrante ( $33 \%$ en el caso de los colombianos, $14 \%$ en los ecuatorianos). En otros casos, los problemas detectados se relacionan con la falta de utilidad práctica del curso, ya que se plantea muchas veces más como una conveniencia de la oferta, de cara a transmitir unos conocimientos establecidos según una norma docente, que como una necesidad de los inmigrantes, como necesidades que tienen los demandantes de insertar los conocimientos recibidos en la práctica laboral. En efecto, más de un $40 \%$ de los colombianos apreciaron una limitación a su utilidad debido a la falta de carácter práctico.

En definitiva, y más allá de cualquier dificultad a la hora de realizar cursos de formación, para los inmigrantes latinoamericanos estos cursos son una forma de conseguir una mejora en el empleo futuro: más del $81 \%$ de los colombianos y casi el $88 \%$ de los ecuatorianos así lo consideran, independientemente de que ya hayan realizado cursos o no, siendo bastante clara la relación entre quienes no declaran interés por hacer cursos en el futuro y el menor nivel de estudios (casi el 30\% tiene estudios primarios incompletos o son analfabetos). La situación contraria también es cierta: a mayor nivel de estudios mayor interés en la formación futura de cara a la mejora en el empleo. Parece razonable suponer que la consolidación de expectativas del proyecto inmigratorio se produce a medida que la estancia se hace más duradera en Madrid y, en este caso, la importancia de los cursos como instrumento de asentamiento de la formación para el empleo en el futuro está significativamente relacionada con la estancia en Madrid: en los primeros años se evalúa esta necesidad en porcentajes bajos, pero crecientes hasta los cinco años, momento en el que casi el $60 \%$ de los colombianos y ecuatorianos estima más adecuado completar su formación para el empleo. Cuando los trabajadores latinoamericanos van consiguiendo sus objetivos económicos, se va asentando el proyecto migratorio en otras esferas, con la posible reagrupación familiar, las expectativas laborales tienden a estabilizarse y a ello contribuyen de forma esencial la formación para el empleo adquirida en Madrid.

\section{¿Hay una acción política de apoyo?}

La inmigración en Madrid tiene ya establecidas sus redes asociativas y sociales que sirven, entre otras funciones, para proporcionar el apoyo adecuado 
para superar las limitaciones que pueden tener los inmigrantes cuando pretenden acceder a los servicios sociales, en este caso, los cursos de formación. De la misma manera, los ayuntamientos de municipios de tamaño más grande tienen establecidas unidades administrativas que facilitan el acceso de los inmigrantes a prestaciones municipales. Asociaciones y ayuntamientos son ya vistos por los propios inmigrantes como sus más fieles aliados para superar algunas de sus más claras limitaciones.

Ayuntamientos y asociaciones tienen, entre sus funciones, la de crear condiciones en las que los inmigrantes se reconozcan como usuarios de derechos (acceso a los servicios, cursos, actividades,...) no coartados por la falta de papeles:

... estaría bien que se apoyara la formación sin tener que estas personas necesariamente estar inscritas... (Asociación Candelita, Colombia).

... partimos tanto aquí como en servicios sociales del principio de normalización, que quiere decir ellos igual que todos, con lo cual cualquier persona que vive aquí en España, tiene acceso a lo mismo (Ayuntamiento de Fuenlabrada).

Y los inmigrantes latinoamericanos encuestados reconocen que la Comunidad de Madrid, el Ayuntamiento de Madrid y otros ayuntamientos de la región son las instituciones públicas que deben ofrecer cursos de formación para inmigrantes (gráfico 8).

Gráfico 8. ¿QUUín CREe que debería impartir los cursos?

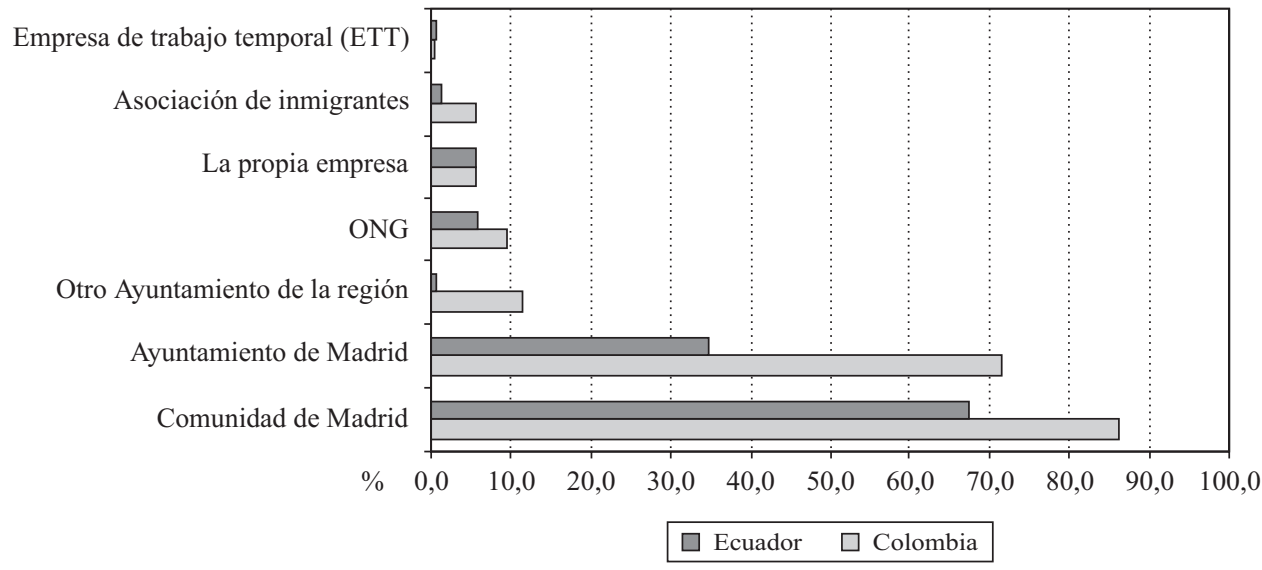

Fuente: IFECAM. Elaboración propia. 
Es previsible que los inmigrantes no lleguen a distinguir el organismo promotor y bajo qué programa, ni cuál es el organismo que lo imparte, pero sí tienen claro que pertenecen a la esfera pública. Pero también es posible que las escasas respuestas de inmigrantes que se decantan por otras instituciones privadas o semiprivadas, en el entorno de los propios inmigrantes, como las ONGs o asociaciones de inmigrantes, apenas un $8 \%$, sean identificadas como centros que imparten los cursos pero que no son los promotores de los mismos. Es claro que la estructura del sistema de oferta e impartición de cursos puede favorecer esta indefinición entre promoción y gestión de los cursos de formación para el empleo.

En definitiva, las expectativas futuras por realizar cursos que mejoren la formación están claramente condicionadas por el tiempo de estancia en Madrid, su nivel educativo y su situación laboral.

\section{CONCLUSIONES}

Con el telón de fondo de la crisis económica global en 2008, se están produciendo cambios en la política migratoria en España ${ }^{14}$. En este contexto, los más afectados son los inmigrantes ${ }^{15}$ que encuentran cada vez mayores dificultades para conseguir un empleo y permanecer en él, o para poder mejorarlo. Una parte importante de los inmigrantes encuestados, con o sin formación adecuada, se encuentra en situación laboral precaria, está siendo afectada por el deterioro de las condiciones del mercado de trabajo secundario y no disfruta de oportunidades comparables a los autóctonos en el mismo, a pesar de que

14 En diciembre de 2008, se presentó el proyecto de reforma de la Ley de Extranjería que prevé el endurecimiento de las reagrupaciones familiares y la prolongación del período de internamiento de los extranjeros en situación irregular. Con la aprobación de la reforma de la actual ley, los inmigrantes sólo podrán reagrupar a su familia una vez que hayan cumplido cinco años de residencia legal en España. Y ésa no es la única restricción que incluye la reforma de la ley, que vetará que los inmigrantes reagrupen a sus padres si éstos tienen menos de 65 años. En cuanto a la reagrupación de los hijos en edad escolar, la reforma establecerá la obligación de que la familia notifique esa llegada con tiempo para que las escuelas o institutos puedan prever el aterrizaje de nuevos alumnos.

15 España ha registrado un fuerte crecimiento económico en la última década, atrayendo a los extranjeros, pero ha sufrido una brusca desaceleración en el último año, que se ha traducido en un aumento del desempleo, especialmente en la construcción, que afecta especialmente al colectivo de trabajadores inmigrantes, cuya tasa de paro se situó en el 17,5\% en diciembre de 2008 , afectando a más del $30 \%$ de los extranjeros en paro y el $24 \%$ de todos los trabajadores del sector de la construcción (Datos del INEM, http://www.inem.es/inem/cifras/datos_avance/doc/empleo/dbprsypr_e.doc). 
hoy muchos viven en España en situación legal. No ha logrado una inserción estable en el mercado de trabajo, dado el grado de incertidumbre de la continuidad en el trabajo o en las condiciones laborales en los sectores en los que estos inmigrantes son dominantes.

Muchos inmigrantes están cualificados para desempeñar puestos de trabajo de nivel superior a los que se ven obligados a aceptar. Entre las razones que contribuyen a ese desajuste entre la formación, cualificación del trabajo y la del puesto de trabajo se cuentan, en muchos casos, el no reconocimiento de los títulos obtenidos, los prejuicios y la discriminación condicionados por la necesidad insoslayable de los inmigrantes de fundamentar las bases económicas en las que han basado su proyecto migratorio. Para reducir estos desajustes, es importante facilitar la entrada legal de la inmigración laboral, para lo cual los países de origen tendrían que seleccionar las personas cuya formación y experiencia se adapte a las necesidades de mercados de trabajo específicos, como el madrileño. Es importante desarrollar y perfeccionar la opción de entrada legal para búsqueda de empleo, para lograr, asimismo, una reducción del flujo irregular de entrada y avanzar hacia un sistema controlado y relacionado con las necesidades del mercado laboral autóctono. Otro objetivo importante para seguir la inserción laboral de los inmigrantes latinoamericanos podría ser la implementación, en la Administración pública, de medidas que favorezcan la movilización de recursos públicos, privados, económicos, sociales, asociativos, culturales.

La mejora formativa se convierte en el valor más necesario en el contexto actual, dado que sólo los inmigrantes mejor formados tendrán acceso a un mercado laboral cada vez más afectado por la crisis y el desempleo. Los inmigrantes encuestados, a pesar de su apreciable estado de vulnerabilidad laboral, están poco interesados en realizar cursos, aunque su interés va creciendo a medida que se alarga el tiempo de estancia en España, ya que el porcentaje de los que afirman realizar cursos cuando llevan más de cinco años duplica al declarado por los inmigrantes con menor tiempo de estancia en Madrid. El discurso de los inmigrantes latinoamericanos, cuando sirve para justificar su decisión de no hacer cursos, se estructura en torno al desinterés, a la falta de planificación o a la confusión relacionada con el desconocimiento de la existencia de cursos por parte de los inmigrantes, tamizado por las informaciones, interesadas o sesgadas, o incompletas que les llegan. Para los inmigrantes encuestados, los ayuntamientos y asociaciones cumplen funciones esenciales para la creación de condiciones en las que éstos se identifiquen como usuarios de derechos, en este caso el acceso a los servicios, cursos, actividades, que no sean limitados por la falta de papeles, o por la rigidez de la oferta formativa reglada. 
Sin lugar a dudas, el organismo idóneo para gestionar cursos de formación para inmigrantes, en las condiciones de desempleados, es el Servicio Regional de Empleo madrileño, puesto que necesariamente tienen que recurrir a él para apuntarse como demandantes de empleo y entonces pueden acceder a sus canales de información sobre cursos. Los cursos de formación continua, que no pertenecen a dicho organismo, sí van dirigidos hacia inmigrantes pero necesitan de la autorización de sus empleadores, por lo que se ven obligados a superar aún un mayor número de más limitaciones de acceso.

No obstante, la oferta de cursos existe pero se encuentra desestructurada y es difícil de llegar a ella. Posiblemente sea ésta una de las razones por las cuales se han utilizado más los mecanismos y redes sociales como medio de información utilizado por los inmigrantes para acceder a los cursos, como señalaron mayoritariamente en la encuesta las personas que declararon haber participado de algún curso de formación para el empleo.

En el futuro, los cursos están considerados por los inmigrantes como un instrumento de primera magnitud para conseguir una mejora en el empleo, tal y como lo declaran la mayor parte de los entrevistados colombianos y ecuatorianos. Sería necesario instaurar cursos de formación en horarios compatibles con el trabajo; cursos de fin de semana, dirigidos a conseguir y potenciar habilidades para encontrar, mejorar y mantener el empleo sobre todo en aquellos sectores más necesitados de mano de obra extranjera. En la coyuntura económica actual, se ha de potenciar la formación ocupacional de carácter práctico, para que los inmigrantes en paro puedan salir de la precariedad y (re)colocarse en sectores de actividad que demandan mano de obra.

\section{BIBLIOGRAFÍA}

Agrela, Belén, Spain as a Recent Country of Immigration: How Immigration Became a Symbolic, Political and Cultural Problem in the "New Spain», Working Paper No. 57, San Diego, USA, The Center for Comparative Immigration Studies, 2002.

Amuedo-Dorantes, Catalina, Sara de la Riza, «Labor Market Assimilation of Recent Immigrants in Spain», British Journal of Industrial Relations, 45/ 2 (Londres, 2007): 257-284.

Arellano, María, La inserción social de las inmigrantes latinoamericanas en España. Migraciones laborales y género, Tesis doctoral, Universidad Complutense, 2004.

Balch, Alex, «Spain», Niessen y Schibel (ed.), Immigration as a labour market strategy. Europe and North America perspectivas, Migration Policy Group, Bruselas, 2005, 35 p. 
Cabo, Gema, «Mujeres inmigrantes en los hogares madrileños, ¿cómo atienden a sus familias?», Las mujeres protagonistas de la inmigración latinoamericana en Espa$\tilde{n}$ a, perspectivas, políticas y experiencias en dos orillas, Casa de América, Madrid, 2006: 49-64.

Cachón, Lorenzo, Inmigración y segmentación de los mercados de trabajo en España, Sevilla, Fundación Centra, Documento de Trabajo S2003/02, 2003.

Cachón, Lorenzo, (2006) «Inmigración y mercado de trabajo en España en la última década (1996-2006)», Gaceta Sindical. Reflexión y Debate, 7 (Madrid, 2006): 241-272.

Carrasco Carpio, Concha, Mercados de trabajo: los inmigrantes económicos, Madrid, Ministerio de Trabajo y Asuntos Sociales, 1998.

Carrasco, Raquel y Carolina Ortega, La inmigración en España: características y efectos sobre la situación laboral de los trabajadores nativos, Madrid, Fundación Alternativas, Documento de Trabajo 80/2005, 2006.

Carrasco, Raquel, Juan Francisco Jimeno y Carolina Ortega, El efecto de la inmigración en las oportunidades de empleo de los trabajadores nacionales: Evidencia para España. Madrid, Fundación BBVA, Documento de Trabajo 1, 2006.

Colectivo IOÉ, Inmigración y trabajo en España. Trabajadores inmigrantes en el sector de la hostelería, Madrid, Observatorio Permanente de la Inmigración, Ministerio de Trabajo y Asuntos Sociales, 1999.

Colectivo IOÉ, Inmigración, escuela y mercado de trabajo. Una radiografía actualizada, Barcelona, Fundación La Caixa, Colección Estudios Sociales, 11, 2002.

Colectivo IOÉ, «Inmigrantes extranjeros en España. ¿Reconfigurando la sociedad?» Panorama Social, 1 (Madrid, 2005): 32-47.

Colectivo IOÉ y J. I. Gil, La inmigración extranjera en el sector de la construcción de Madrid. Su situación desde la perspectiva de la seguridad y salud laboral, Madrid, Fundación Laboral de la Construcción, 2005.

Tornos Cubillo, Andrés, Rosa Aparicio Gómez y Mercedes Fernández García. El capital humano de la inmigración, Madrid, Instituto de Migraciones y Servicios Sociales, 2004.

Domingo, Andreu y René Houle, «La actividad de la población de nacionalidad extranjera en España: entre la complementariedad y la exclusión», $4{ }^{\circ}{ }^{\circ}$ Congreso de la Inmigración en España, Girona, 2004: 11-39.

Domingo, Andreu, Tras la retórica de la hispanidad: la migración latinoamericana en España entre la complementariedad y la exclusión, Barcelona, Centro de Estudios Demográficos, 2005.

García Ballesteros, Aurora y Bernardino Sanz Berzal, Inmigración y sistema productivo en la Comunidad de Madrid, Madrid, Consejería de Economía e Innovación Tecnológica, Comunidad de Madrid, 2004. 
Gil, Fernando y Andreu Domingo, «La participación de los ciudadanos latinoamericanos en el mercado de trabajo español: características diferenciales y evolución reciente (2000-2005)», V Congreso sobre la Inmigración en España, Valencia, 2007: 443-459.

Gómez Ciriaco, E. J. et al., Ecuatorianos en España. Una aproximación sociológica, Madrid, Documentos del Observatorio Permanente de la Inmigración, n. ${ }^{\circ} 15$. Ministerio de Trabajo e Inmigración, 2007.

Herranz Gómez, Yolanda, Formas de incorporación laboral de la inmigración latinoamericana en Madrid. Importancia del contexto de recepción, Tesis doctoral, Universidad Autónoma de Madrid, 1996.

Izquierdo, Antonio y Belén Fernández, «Inmigración», Informe 2007, Madrid, Observatorio Social de España, Biblioteca Nueva, 2007: 847-886.

Jokish, Brad y Jason Pribilsky, «The panic to leave: economic crisis and the "new migration" from Ecuador», International Migration, 40/ 4 (New York, 2002): 75-101.

Martínez Veiga, Ubaldo, Trabajadores invisibles. Precariedad, rotación y pobreza de la inmigración en España, Madrid, Los Libros de la Catarata, 2004.

Morillas Gómez, Javier, Mercado de trabajo e inmigración. Los servicios a los hogares en el ámbito del empleo doméstico en la Comunidad de Madrid, Madrid, Universitas, 2007.

Pajares, Miguel, Inmigración y mercado de trabajo del año 2008, Madrid, Ministerio de Trabajo e Inmigración, 2008.

Parella Rubio, Sonia, Mujer, inmigrante y trabajadora: la triple discriminación, Barcelona, Anthropos, 2003.

Pérez Carames, Antia, «Los residentes latinoamericanos en España: de la presencia diluida a la mayoritaria», Papeles de Población, n. 41 (México, 2004): 259-295.

Pérez Infante, José Ignacio, «El marco legal y la problemática del empleo de los extranjeros en España: una perspectiva económica», V Congreso de la Inmigración en España, Valencia, 2007: 359-401.

Setién María-Luisa y López, Arantxa, Mujeres inmigrantes y formación: perspectivas europeas, Universidad de Deusto, Bilbao, 2002.

Solé, Carlota. Inmigración, mercado de trabajo y género, Sevilla, Fundación Centra, Documento de Trabajo Serie Sociología S2003/01, 2001, 22 p.

Solé, Carlota y Sonia Parella, «The labour market and racial discrimination in Spain», Journal of Ethnic and Migration Studies, 29/ 1 (London, 2003): 121-140.

Tezanos, José Félix, Condiciones laborales de los trabajadores inmigrantes en España, Madrid, Ministerio de Trabajo y Asuntos Sociales, 2007.

Vallecillo Gámez, María Rosa, «Trabajadores inmigrantes y Empresas de Inserción: por un nuevo modelo de integración sociolaboral», REDSI, Revista especializada 
en Formación y Empleo de los Colectivos en Riesgo de Exclusión, n. 5 (Madrid, diciembre de 2004): 67-89.

\section{LABOUR MARKET AND TRAINING AMONG LATIN AMERICANS IN THE COMMUNITY OF MADRID}

This paper analyses the relation between training and employment in the Community of Madrid (CAM) of immigrants from Ecuador and Colombia. The first part of the paper deals with the imbalance between training and employment, stressing the immigrants' level of training in their countries of origin, whereas the second part analyses the need and value of training in order to have access to labour market in Madrid. By analysing the discourse of immigrants and specialists in this field (via thorough interviews and focus groups), it is possible to go further into the discussion about the present situation and prospects of labour market and immigration, on the one hand, and, on the other hand, about the challenges and limitations of socio-labour intervention as a means to the integration of the Latin American community.

KEY WORDS: Latin American immigrants, training and employment, Community of Madrid, labour market. 